\title{
Aportes para el estudio del Teatro Libre de Buenos Aires (1944-1947)
}

\section{Contributions to the Study of the Free Theater of Buenos Aires (1944-1947)}

Artículo recibido el 29 de marzo de 20I9; aceptado el II de marzo de 2020; https://doi.org/IO.2220I/ iie.18703062e.2020.117.2730

María Fukelman Universidad de Buenos Aires, Facultad de Filosofía y Letras / Instituto de Artes del Espectáculo / Consejo Nacional de Investigaciones Científicas y Técnicas / Universidad Católica Argentina / mariafukelman@ gmail.com, https://orcid.org/oooo-0003-0319-187X

Líneas de investigación Teatro argentino; historia del teatro; teatro independiente.

Lines of research Argentine Theater; Theater History; Independent Theater.

Publicación más relevante "Mujeres en la historia del movimiento de teatros independientes de Buenos Aires: aportes para la historia de La Cortina y el Teatro Espondeo", en Revista Interdisciplinaria de Estudios de Género de El Colegio de México, vol. 4, e290 (2018): I-28.

Resumen El teatro independiente surgió en Buenos Aires a principios de la década de los ańos treinta como un modo de producir y de concebir el teatro que pretendió renovar la escena nacional de tres maneras: se diferenció del teatro que ponía los objetivos económicos por delante de los artísticos; se propuso realizar un teatro de alta calidad estética; careció de fines lucrativos. En este sentido, se constituyó como una práctica colectiva y contestataria, oponiéndose al statu quo del teatro de aquellos años e impulsando una organización anticapitalista, pero también heterogénea, ya que se mostró como un entramado complejo y rico en su diversidad. De acuerdo con esto, abordaré el estudio de un caso particular: el Teatro Libre de Buenos Aires, creado en 1944 por Roberto Pérez Castro.

Palabras clave teatro independiente; Teatro Libre; Roberto Pérez Castro; Buenos Aires; heterogeneidad; archivo; Juan Domingo Perón.

Abstract Independent theater emerged in Buenos Aires at the beginning of the I930's as a way to produce and conceive a theater that wanted to renew the national stage by three means: breaking away from conventional 
theater, placing artistic objectives before economic ones, and by aspiring for a non-profit theater of high aesthetic quality. It was conceived as a collective and defiant practice in opposition to the status quo of the period's theater, and as anti-capitalist, yet as a heterogeneous organization, while revealing itself as complex and rich in diversity. The article addresses a particular case: The Free Theater of Buenos Aires, created in 1944 by Roberto Pérez Castro.

Keywords independent theater; Teatro Libre; Roberto Pérez Castro; Buenos Aires; heterogeneity; archive; Juan Domingo Perón. 


\author{
MARÍA FUKELMAN \\ UNIVERSIDAD DE BUENOS AIRES / \\ CONSEJO NACIONAL DE INVESTIGACIONES CIENTÍFICAS Y TÉCNICAS / \\ UNIVERSIDAD CATÓLICA ARGENTINA
}

\title{
Aportes para el estudio del Teatro Libre de Buenos Aires (1944-1947)
}

$\mathrm{E}$

$\mathrm{n}$ mi tesis de doctorado, ${ }^{\mathrm{I}}$ he definido la poética abstracta del teatro independiente como lo hice en el resumen de este artículo. Esta caracterización fue fruto del análisis comparativo entre nueve grupos de teatro independiente que existieron entre 1930 y i944: el Teatro del Pueblo (1930), el Teatro Proletario (I932), el Teatro Juan B. Justo (I933), el Teatro Íntimo de La Peña (I935), el Ift (Idisher Folks Teater, I937), La Cortina (I937), el Teatro Popular José González Castillo (1937), La Máscara (1939) y el Teatro Espondeo (I94I). A estos grupos los estudié a partir de seis ejes de análisis: I) génesis; 2) estética; 3) cultura y educación; 4) vínculos con el teatro profesional y los recursos económicos; 5) relaciones con el Estado y los partidos políticos, y 6) inserción dentro del movimiento de teatros independientes. Los apartados sobre algunos grupos, como el Teatro Juan B. Justo, el Teatro Íntimo de La Peńa y el Teatro Espondeo, resultaron ser las primeras sistematizaciones realizadas sobre ellos, en tanto que no existía bibliografía específica. Estos aportes fueron posibles mediante el procesamiento de la bibliografía general existente, de un exhaustivo trabajo de análisis de las fuentes y de cierto particular interés en el material de archivo. En este sentido, para el desarrollo de mi tesis, no solamente

I. María Fukelman, "El concepto de 'teatro independiente' en Buenos Aires, del Teatro del Pueblo al presente teatral: estudio del periodo 1930-1944", tesis de doctorado (Buenos Aires: Universidad de Buenos Aires-Facultad de Filosofía y Letras, 2017). 
visité bibliotecas y centros de documentación, sino que también intenté hacer contacto con algunos familiares de antiguas figuras del teatro independiente.

Fue así como, buscando información sobre el Teatro Juan B. Justo, llegué, por medio de Leandro Agilda — sobrino biznieto de quien fuera uno de sus directores más importantes, Enrique Agilda-, hasta Nélida Agilda y su hija Noemí Pérez Agilda. Nélida, además de haber sido colaboradora del Teatro Juan B. Justo y de ser la sobrina de Enrique Agilda, había sido la esposa de Roberto Pérez Castro, otra figura reconocida del teatro independiente. Noemí es la hija de ambos. Por medio de estas dos mujeres, entonces, adquirí fotos, programas de mano y documentación sobre el Teatro Juan B. Justo y también sobre los cuatro teatros independientes creados por Pérez Castro: el Teatro Libre de Buenos Aires (1944-1947), el Teatro Estudio (1950-1953), el Teatro Expresión (1954) y el TPI (Teatro Popular Independiente, I956-1963). Entre ellos, me interesó en particular el primero, el Teatro Libre de Buenos Aires, por coincidir con el periodo que en la actualidad me encuentro investigando con la beca posdoctoral del CONICET (1945-I955) y por ser un conjunto muy bien catalogado, pero que no ha sido estudiado. Si bien este grupo no duró mucho, me parece que recuperar su (breve) recorrido constituirá un aporte para la historia del movimiento de teatros independientes. De manera que, en el presente trabajo, me centraré en el estudio del Teatro Libre y lo abordaré con los mismos ejes de análisis con los que trabajé los anteriores nueve grupos. ${ }^{2}$

\section{Génesis}

Roberto Pérez Castro se inició como actor en 1942 en el Teatro Juan B. Justo, y permaneció en dicha agrupación hasta su disolución definitiva, en 1944. El 24 de agosto de este mismo año - a sus 29 inviernos- fundó el Teatro Libre de Buenos Aires, junto a Roberto Aulés y otros jóvenes colegas.

El nombre del grupo es el aspecto inicial por analizar. En principio, remite al que considero el primer antecedente europeo del teatro independiente porteño. Me refiero al Théâtre-Libre, de París, creado por André Antoine, en 1887. Este grupo surgió como un laboratorio experimental y como un teatro de provocación, ya que se enfrentaba al teatro oficial de la Comedia Francesa

2. Agradezco a Nélida Agilda y a Noemí Pérez Agilda por haberme cedido y permitido documentar la totalidad de su material de archivo. 
y a los escenarios "comerciales" del Boulevard. Estableció un modelo de teatro realista y se especializó en dramas de tesis. A su vez, se ubica a la par de otros de nombres y experiencias similares — como Die Freie Bühne (Berlín, 1889) y The Independent Theatre Society (Londres, I89I)—, dentro de la primera de las tres corrientes en las que he clasificado ${ }^{3}$ el accionar de los que se pueden catalogar como antecedentes europeos de nuestro teatro independiente: teatro libre/independiente; teatro de arte; teatro popular.

El concepto de "teatro libre" o "teatro independiente" que surgió en Europa y que, más adelante, Leónidas Barletta y otras figuras propusieron para la escena porteńa, tiene que ver con un nuevo modo de pararse en el campo teatral y con una postura política tomada por los artistas. Estas nuevas prácticas se distanciaban del teatro que producía el Estado y del realizado por empresarios para entretener. A diferencia de estas modalidades, el "teatro libre" señalaba que tenía algo para decir y que quería hacerlo con la mayor verdad posible. En este sentido, sus hacedores rechazaban la figura de los capo-cómicos y ciertos recursos actorales, como el estilo interpretativo, la afectación, la declamación, la exageración y el "morcilleo" (improvisación de la letra, típica del teatro "comercial", que solía usarse para hacer reír al público). Promovían la moderación de los actores en escena. Además, se oponían a los decorados prototípicos que se utilizaban (en general, "cartón pintado") y consideraban que la práctica teatral no era un juego de aficionados.

Por otro lado, con el nombre de Teatro Libre también se conoció a otra agrupación, surgida en Buenos Aires, en abril de 1927, a la que tomo como un antecedente porteño del Teatro del Pueblo, grupo creado en 1930 por Leónidas Barletta y considerado por la crítica como el primer teatro independiente de Buenos Aires. Esta experiencia, llevada a cabo por el propio Barletta, Elías Castelnuovo, Guillermo Facio Hebequer, Octavio Palazzolo, Augusto Gandolfi Herrero, Abraham Vigo, Álvaro Yunque y Héctor Ugazio, no prosperó con el tiempo. Llegó a hacer algunas declaraciones públicas y a anticipar que estrenaría una obra dirigida por Palazzolo, pero eso nunca aconteció.

Estas referencias pudieron haber servido de inspiración para Roberto Pérez Castro a la hora de denominar a su grupo. No obstante, es posible que la elección también haya tenido que ver con una postura política respecto de los conceptos "teatro independiente" y "teatro libre": de Buenos Aires", Acta Literaria, núm. 54 (primer semestre, 2017): 159-178. 
Ya en otras oportunidades establecí la razón de por qué consideraba más apropiado determinar teatros "Libres" y no "Independientes" a esos organismos un [tanto] románticos que tratan de imponer una moral y una superación honrada para el arte teatral.

Dije entonces y hoy lo repito más convencido, que la independencia no depende de nosotros pues siempre se condiciona a la buena voluntad de los demás o bien la determinan diferentes factores circunstanciales.

En cambio, el sentirse libre o no es algo propio de cada uno, y nada ni nadie puede influir en ese íntimo sentimiento. Podrán postergarse nuestros anhelos de libertad y rebeldía ante el cúmulo de obstáculos que la vida nos presenta — vemos que a diario así sucede - pero dudo que la suma de esos inconvenientes conforme un alma esclava. ${ }^{4}$

Al haberse manifestado a favor del término "libre" por sobre su supuesto sinónimo, se puede pensar que la intención de darle fuerza a tal categoría fue lo que inclinó la balanza en el momento de bautizar al grupo. Sin embargo, es importante destacar que, desde sus inicios, el Teatro Libre de Buenos Aires se ubicó dentro del movimiento de teatros independientes. ${ }^{5}$

Roberto Pérez Castro fue un hombre muy prolífico en su escritura, por tanto existen numerosos documentos, a título personal o grupal, en los que se pueden vislumbrar los propósitos del Teatro Libre. En ellos se habla sin tapujos de sus objetivos artísticos y sociales, y no se pretende separar su surgimiento de la coyuntura histórica nacional e internacional, sino que, por el contrario, el mismo grupo se reconoce como fruto de un contexto:

Agosto 1944. A pesar del clima de destrucción, de intranquilidad y de pesimismo que favorecía la dictadura, conservábamos nuestra fe en el hombre y en la parábola de su destino, y comprendimos que era preciso luchar - ley inexorable - contra los que pretendían debilitar esa fe.

Surgió entonces la idea de crear un Teatro Independiente con la misión cardinal de elevar la sensibilidad del pueblo y defender su libertad. Para concretar este

4. Archivo personal de Roberto Pérez Castro (en adelante Archivo personal), "Destino del Teatro Libre", recorte periodístico, julio de 1947, s. p.

5. Véase Teatro Libre de Buenos Aires, Teatro Libre de Buenos Aires. Esencia y función, I (Buenos Aires: Ediciones del Teatro Libre de Buenos Aires, 1946). 
proyecto nos citamos en aquellos días venturosos de la liberación de París. Pero no fue posible reunirse: ese 23 de agosto la ciudadanía electrizaba el ambiente con su entusiasmo, y todos nosotros compartimos idéntica vibración de esperanza. $\mathrm{Y}$ al volver reconfortados a nuestras ansias de paz y de trabajo, ya estaba asegurado en las pupilas el brillo inconfundible de la fe y en los corazones la voluntad inquebrantable de ser libres frente a cualquier tiranía.

Forjado en esa fe y en esa voluntad, el nuevo teatro serviría a su tiempo y a su pueblo, del mismo modo que sus fundadores. Y se llamó "LIBRE": Libre en la independencia del espíritu: libre para ser fiel a la verdad. ${ }^{6}$

El Teatro Libre de Buenos Aires, que tuvo su sede en Viamonte 256I (en el local de la Asociación Nueva Argentina), se mantuvo vigente hasta 1947, y las palabras que le dedicó parte de la crítica fueron muy elogiosas. Por ejemplo, a más de un año de que iniciara sus funciones, Luis Ordaz dijo:

Entre los grupos surgidos últimamente debe ser nombrado el Teatro Libre de Buenos Aires que, aparte de la simpatía que inspira la juventud de todos sus componentes, ha realizado espectáculos en donde puso de manifiesto el fervor humano y la responsabilidad artística que lo alienta y da forma. ${ }^{7}$

El lema que guió a los integrantes fue la frase de Francisco Giner de los Ríos: "Nobleza en los fines, honradez en los medios, desinterés en los móviles", aunque también utilizaron dichos de distintas personalidades (como Romain Rolland, Federico García Lorca, Stefan Zweig y Jesús) para armar tarjetitas que distribuían gratuitamente entre el público, a modo de souvenires. En uno de los documentos conservados, las "Bases provisorias" del grupo - cuyos fragmentos continuaré exponiendo a lo largo de este trabajo-, se hace hincapié en la necesidad de "crear una conciencia artística social de profunda raigambre humana" y en la pretensión de transmitir valores solidarios y colectivos por sobre el "individualismo estéril". ${ }^{8}$

6. Véase Teatro Libre de Buenos Aires. Esencia y función, I, s. p.

7. Luis Ordaz, El teatro en el Río de la Plata (Buenos Aires: Futuro, 1946), I83.

8. Archivo personal, Teatro Libre de Buenos Aires, "Bases provisorias para el grupo Teatro Libre de Buenos Aires", mecanoescrito, s. f., s. p. 


\section{Estética}

\section{Repertorio}

En las "Bases provisorias" del Teatro Libre de Buenos Aires se señala el objetivo de "difundir la buena literatura y el buen teatro sin distinción de épocas o nacionalidades, y entregarlo puro y vigorizado al pueblo". 9 En esta frase hay varios puntos para tener en cuenta. En principio se retoma una premisa básica de los inicios del teatro independiente: la idea de que el arte es puro y de que se transporta desde los artistas hasta el público. Esto puede vislumbrarse desde las manifestaciones públicas iniciales del Teatro del Pueblo, donde en el artículo $2^{\circ}$ de sus estatutos se expresaba que sus objetivos eran: "Experimentar, fomentar y difundir el buen teatro, clásico y moderno, antiguo y contemporáneo, con preferencia al que se produzca en el país, a fin de devolverle este arte al pueblo en su máxima potencia, purificándolo y renovándolo." ${ }^{\circ}$ Además, en ambas declaraciones se sostiene que hay (o debería haber) un "buen teatro", el que, imagino, se contrapone al "mal teatro". Estas ideas, la de realizar un teatro de alta calidad estética y la de ubicar al pueblo en el centro de la escena, nos remontan a las segunda y tercera líneas - teatro de $\operatorname{arte}^{\mathrm{II}} \mathrm{y}$ teatro popular, ${ }^{12}$ mencionadas en el presente trabajo y desarrolladas con mayor profundidad con anterioridad - de los antecedentes europeos del teatro independiente porteño. ${ }^{\mathrm{I3}}$

Asimismo, los dos extractos se refieren a la dramaturgia que elegirán, aunque, en el caso del Teatro Libre de Buenos Aires, la preferencia es, precisamente, no tenerla. El repertorio se presenta, entonces, como algo muy variado. A modo de representación gráfica de esa variedad podemos pensar el modo de llevar a escena las piezas seleccionadas que tuvo el Teatro Libre de Buenos Aires.

9. Archivo personal, Teatro Libre de Buenos Aires, "Bases provisorias para el grupo Teatro Libre de Buenos Aires", mecanoescrito, s. f., s. p.

Io. Raúl Larra, Leónidas Barletta. El hombre de la campana (Buenos Aires: Ediciones Conducta, 1978), 8I.

II. La segunda línea de los teatros de vanguardia europeos que luego se retomó en Buenos Aires tuvo que ver con la pretensión de realizar un "teatro de arte" o "arte bello". La mayoría de estos exponentes sostuvo el propósito de experimentar, aunque no todos se autodenominaron "vanguardia".

I2. Los propulsores de este concepto ubicaron al pueblo como su destinatario central y sus acciones viraron en torno a la construcción de un teatro que fuera accesible para todos.

I3. Véase Fukelman, "Influencias del teatro europeo", I59-I78. 
De hecho, éste es uno de los puntos más novedosos del grupo. Roberto Pérez Castro explicó su creación de "una especie de periódico escénico que procuró reflejar la realidad artística y social del país". ${ }^{14}$ Esto también se había expresado en las "Bases provisorias", donde se afirmaba que para cumplir con los propósitos señalados se iba a trabajar "por medio de publicaciones orales, con base esencialmente teatral, a fin de que la tarea llegue mejor al especta-

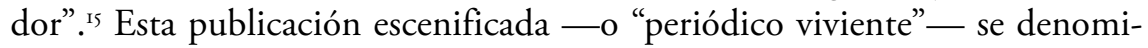
nó Estudio. Publicación Escenificada. Allí se expusieron páginas destacadas de literatura (no sólo literatura dramática) argentina y extranjera, y también producciones propias.

Para preparar su primer espectáculo, el Teatro Libre de Buenos Aires llevó a cabo una exhaustiva investigación, que incluyó la realización de inventarios sobre los libros de teatro disponibles en sus bibliotecas, su clasificación, y la posterior sistematización de ficheros de bibliografía, y de autores, directores y actores-directores "de valor positivo". ${ }^{16}$ Antes de eso, el grupo había realizado otro trabajo previo, destinado a conocer los distintos aspectos del teatro (de autoría, actuación, realización escenográfica, dirección, técnica en iluminación) y a entender las interrelaciones entre ellos.

El 22 de junio de 1945, luego de "diez meses de investigaciones pacientes realizadas en el silencio de las bibliotecas, de numerosas discusiones artísticas, de agotadores trabajos de toda índole", ${ }^{17}$ el grupo estrenó la primera edición de Estudio. Publicación Escenificada, cuyo programa se ordenó de la siguiente manera: I) presentación; 2) Platero y yo, estampas ilustradas de la elegía de Juan Ramón Jiménez; 3) intermedio musical; 4) nota sobre Teatro Libre ${ }^{18}$ en Europa y en Argentina; 5) El retablo de maese Pedro, un momento de El ingenioso hidalgo Don Quijote de la Mancha, de Miguel de Cervantes Saavedra; 6) Nacimiento de Esperanza, poema de la colonización de José Pedroni; 7) intermedio

I4. Archivo personal, Roberto Pérez Castro, "Destino del Teatro Libre", recorte periodístico, julio de 1947 , s. p.

15. Archivo personal, Teatro Libre de Buenos Aires, "Bases provisorias para el grupo Teatro Libre de Buenos Aires", mecanoescrito, s. f, s. p.

I6. Archivo personal, Roberto Pérez Castro, "Palabras leídas en la noche del rer Estreno", mecanoescrito, 22 de junio de 1945 .

17. Teatro Libre de Buenos Aires. Esencia y función, I, s. p.

I8. Dada la preferencia semántica de Pérez Castro ya enunciada, se entiende que se estaban refiriendo al teatro independiente en general, y no al Teatro Libre de Buenos Aires en particular. 
musical, y 8) El señor Cuenca y su sucesor, un capítulo de Libro de Singüenza, de Gabriel Miró. Los actores y actrices de la puesta en escena fueron Margarita Jané, Roberto Aulés, Luisa Moljo, Nelli Anzarut, Irma Mucciardi, Alicia Sagredo, José Moljo, Roberto Pérez Castro, Juan Carlos Wall, Pedro M. Luciarte y Tomás Gonda. De los apuntes escenográficos se ocupó D. Lorenzo; de las escenificaciones, Roberto Aulés y Roberto Pérez Castro; de las luces, Simón Coifman; y de la dirección, Pérez Castro.

En ocasión de este estreno, a su vez, el grupo declaró:

El mundo espera la pronta terminación de esta guerra y el comienzo de una etapa de pacificación, que sin duda será dificultosa. En esta etapa de la paz todos debemos colaborar para que sea justa y duradera, junto a los que con tanto entusiasmo y sacrificio están haciendo posible la victoria. ${ }^{19}$

Hay que recordar que, desde 1939, el mundo se encontraba inmerso en la Segunda Guerra Mundial, la cual finalmente terminaría poco más de dos meses después. La guerra fue, para los integrantes del Teatro Libre de Buenos Aires, una preocupación constante, sobre la que volveré más adelante.

Si bien la mayoría de la prensa ignoró el debut del teatro de Pérez Castro, la única crítica, publicada en el diario Hoy - y recuperada por los propios protagonistas en su cuadernillo de extensión cultural—, fue muy positiva, a la vez que analizó la nueva modalidad de trabajo:

Se trata indudablemente de una modalidad que no coincide exactamente con el concepto general de Teatro, pero ello, lejos de restarle mérito contribuye a realzar la labor realizada. No escapa al criterio del espectador más desprevenido las enormes dificultades que implica el llevar al tablado la figura del poeta de "Platero y Yo", de Juan Ramón Jiménez, por ejemplo, sin desvirtuar la dulzura y la belleza que transparentan cada frase de la obra. [...] El elogio, amplio y generoso se brinda en este caso al loable propósito de poner en contacto al público teatral con las obras maestras de la literatura mundial; sí, pero el propósito cristalizado en una labor honesta, respetuosa, dignísima, realizada con fervor y conocimiento; al logro de una auténtica expresión de belleza espiritual sin grandes recursos materiales, puesto que se ha utilizado apropiada decoración sintética. ${ }^{20}$

19. Teatro Libre de Buenos Aires. Esencia y función, I, s. p.

20. Teatro Libre de Buenos Aires. Esencia y función, I, s. p. 
Bernard Marcel Porto, por su parte, también caracterizó la presentación de una revista escenificada como una "originalidad". ${ }^{21}$ Este espectáculo se llevó a escena alrededor de treinta veces.

Un breve tiempo después, el 26 de octubre de 1945, el Teatro Libre de Buenos Aires estrenó su segundo número de Estudio. Publicación Escenifica$d a$. Esta vez, se "compaginó en forma de poder ofrecerlo fuera del local de la calle Viamonte" ${ }^{12}$ y se mostró tanto en la circunscripción $5^{\text {a }}$ del Partido Socialista como en la Federación de Sociedades Gallegas. El programa fue el siguiente: I) Canto eterno de la juventud, de Roberto Pérez Castro; 2) intermedio musical; 3) Llanto por Ignacio Sánchez Mejías, de Federico García Lorca; 4) El teatro independiente (ensayo teatralizado); 5) Si, de Rudyard Kipling, y 6) La isla desierta, de Roberto Arlt. El reparto estuvo compuesto por Pedro M. Luciarte, Carmen Luciarte, ${ }^{23}$ Margarita Jané, Constantino Sotelino, Juan Carlos Wall, Roberto Pérez Castro, Roberto Aulés, Tomás Gonda y Pedro Casais. ${ }^{24}$ La dirección, como siempre, corrió por cuenta de Pérez Castro; y D. Lorenzo y Simón Coifman se ocuparon de los apuntes escenográficos y de las luces, respectivamente.

Este espectáculo, como el anterior, tuvo un solo comentario en los medios. En este caso fue José Marial, el tradicional crítico de teatro independiente, quien le dedicó unas palabras en Orientación. Si bien su análisis mostró altibajos (cuestionó la eficacia y la teatralidad del ensayo sobre teatro independiente, y consideró que a la pieza de Pérez Castro le faltó consistencia escénica), el balance otra vez dio positivo:

Esta agrupación con sus modestos recursos, sabe lo que quiere, cuáles son sus deberes y de dónde proviene el material artístico para su trabajo. Tiene conducta, decisión, empeńo y un esclarecido afán de estudio.

[...] "La isla desierta" del malogrado Roberto Arlt, merece todo nuestro estímulo. Bien la elección, buena la interpretación y suplidos con honestidad y capacidad, los casi insalvables obstáculos que significa montar una obra de esta

2I. Bernard Marcel Porto, "Existencia y dinamismo del teatro independiente", Histonium, núm. 77 (octubre de 1945): 698.

22. Teatro Libre de Buenos Aires. Esencia y función, I, s. p.

23. Tanto Pedro y Carmen Luciarte como Roberto Aulés habían iniciado su carrera en el elenco de adolescentes del Teatro Juan B. Justo.

24. Al igual que Pérez Castro, Casais había integrado el elenco (de adultos) del Teatro Juan B. Justo. 
156 MARÍA FUKELMAN

naturaleza en un tablado reducido como el que dispone esta agrupación. Entre los actores hay elementos de valía. De todos se puede esperar mucho si continúan firmes en el rumbo que se han dado. ${ }^{25}$

Durante este primer año de trabajo, las funciones — cuarenta en total- se realizaron los sábados (a las 2r:30 horas) y los domingos (por la tarde). La temporada terminó el 25 de noviembre; pero en breve se pusieron a trabajar en un nuevo espectáculo.

En febrero de 1946, llegó Guerrillas de la liberación (voces del pueblo), obra que contenía textos y canciones dedicados a España (Llamo a la juventud y Vientos del pueblo, poemas de Miguel Hernández), Rusia (Nuevo canto de amor a Stalingrado, poema de Pablo Neruda), Inglaterra y Estados Unidos (el epílogo de la película El gran dictador, de Charles Chaplin, y Dios que creaste libre al hombre..., palabras de Franklin D. Roosevelt), Francia (El ejército de maquis, Yo soy el futuro y La Marsellesa) y Argentina (Canto eterno a la juventud, de Roberto Pérez Castro, y Canto civil a los contemporáneos de la libertad, de Ernesto Castany). Los intérpretes fueron Roberto Aulés, Pedro Luciarte, Juan Carlos Wall, Carmen Luciarte, Margarita Jané, Constantino Sotelino y Pedro Casais. La dirección estuvo a cargo de Roberto Pérez Castro.

Esta pieza tenía un alto contenido político, en tanto que - evocando disputas internacionales - predicaba la búsqueda de la libertad y el rechazo a los tiranos, y exhortaba al pueblo a sumarse a la lucha. Entre el 2 y el 22 de febrero, se realizaron numerosas representaciones, llegando a hacer hasta tres por día, tanto en lugares cerrados como abiertos de la ciudad de Buenos Aires y fuera de ella. Se visitaron espacios culturales y sindicatos, y se hicieron funciones para estudiantes. El contexto de acción era la campaña para las elecciones presidenciales del 24 de febrero de 1946, en las que, mal que le pesó al Teatro Libre, Juan Domingo Perón fue elegido presidente de la nación. Como señalaré más adelante con mayor profundidad, muchos grupos de teatro independiente tenían tendencias izquierdistas y fueron acérrimos enemigos del peronismo. El estreno de la pieza Guerrillas de la liberación, a diferencia de sus predecesoras, "mereció el elogio de toda la prensa libre de la Capital, incluyendo los diarios de las colectividades extranjeras" ${ }^{26}$ El grupo conservó un recorte del diario $\mathrm{La}$ Prensa (sin firma) a modo de ejemplo:

25. Teatro Libre de Buenos Aires. Esencia y función, I, s. p.

26. Teatro Libre de Buenos Aires. Esencia y función, I, s. p. 
La levantada intención encontró la expresión más concreta en el hermoso espectáculo, de calidad excepcional, de jerarquía, de verdadero valor artístico en su contenido.

Los jóvenes actores, dijeron las vibrantes páginas con breves y muy acertadas escenificaciones, en un acto de claro sentido cívico, de fervor de libertad y democracia, de resistencia y repudio a toda dictadura, pero sin tocar en ningún momento la nota política. Por su calidad y por su propósito digno, es un espectáculo que merece el más amplio apoyo y debe repetirse, aunque convendría, para su mayor agilidad, suprimir o reducir considerablemente, esas finales "estampas de la resistencia". ${ }^{27}$

Asimismo, en las páginas de Tribuna también se destacó al Teatro Libre de Buenos Aires y a su nueva obra:

En un alarde poco común, estos muchachos, casi unos niños, se han enfrentado cara a cara al rosismo y sin abandonar un instante la elevada posición en que el ejercicio de su arte los ha colocado, son autores de la protesta viril más enérgica y valiosa de cuantas ha motivado la situación actual.

A duras penas cuentan en su haber un ańo de puja y ya hicieron teatro del más peligroso, teatro de ese que va a ser carne y sustancia de la vida misma de sus actores, y no teatro de calco ni de componenda.

[...] Éstos y no otros son los ricos y afinados elementos que el Teatro Libre de Buenos Aires ha puesto al servicio de las Guerrillas de la liberación, cúmulo de escenas rápidas, pero de destacada violencia en que se narran tres movimientos ya imperecederos en la conciencia argentina: el martirio de la Espańa eterna, la liberación de París y la marcha de la Constitución y de la Libertad. ${ }^{28}$

Como se desprende de estas palabras, era evidente que los jóvenes integrantes del Teatro Libre de Buenos Aires se estaban oponiendo, desde el escenario, al gobierno de Perón, al que el crítico Jerineldos iguala —en una comparación bastante utilizada - al de Juan Manuel de Rosas (y por esto llama notoriamente la atención la frase "sin tocar en ningún momento la nota política", del diario La Prensa).

27. Teatro Libre de Buenos Aires. Esencia y función, I, s. p.

28. Jerineldos, "Digno de trascender: 'Guerrillas de la liberación”', Tribuna (febrero de 1946): IO-II. 
En 1947, el grupo preparó un homenaje a la España republicana denominado ¿Y España? El tema había sido elegido ante la permanencia de Francisco Franco una vez terminada la segunda guerra mundial y el título es homónimo al de un poema de Rafael Alberti, quien aludía, precisamente, a que había llegado la paz para todos menos para España. ${ }^{29} \mathrm{Al}$ mismo tiempo, presumiblemente por presiones de la embajada franquista, su teatro fue clausurado con la excusa de tener problemáticas en los baños.

Si bien, al representar fragmentos, las piezas que presentó el Teatro Libre fueron variadas, todas estaban unidas por un fin superior: contribuir al sentido común de lo colectivo y ayudar a la transformación de la sociedad por medio del teatro. De esta forma, destacan las palabras que Roberto Pérez Castro plasmó, luego, en uno de sus tantos escritos:

Las obras tienen que tener relación directa con el hombre actual. [...] Éste es justamente el término; el diálogo. [...] Que plantee los problemas eternos del hombre: el hombre y la libertad, el hombre y la sociedad, el hombre y la historia, etc. No desconocemos la importancia de ciertas obras que sólo pueden ser entendidas por minorías selectas. Sencillamente las desechamos, porque no entran en nuestra línea. Preferimos el teatro que vaya a los grandes núcleos. No se confunda esto con populacherismo, con folklorismo o con ultracolonialismo. El teatro es popular en la medida en que refleje con mayor potencialidad un sentir colectivo. En fin, lo social, lo humano, lo general, son los elementos que integran nuestro sentido de lo popular. Evitamos dos tipos de teatro: las recetas comerciales y el teatro para minorías. ${ }^{30}$

29. Este espectáculo se grabó en 1956, cuando empezó el TPI, en una de esas grandes cintas de papel de los primeros grabadores que existieron. Noemí Pérez Castro aún lo conserva (se puede escuchar porque, en los años setenta, lo pasó a un casete); comienza con el relato del triunfo del Frente Popular en febrero de 1936, y tiene poemas, textos, canciones y pequeños diálogos que van uniendo todo el material. Entre los actores figura un jovencísimo Jorge Lavelli. Años después, en 196I, cuando el poeta Marcos Ana estuvo en el Luna Park, Noemí recuerda que estaba con su padre en la tribuna y que él se fue a la casa a buscar los antiguos cancioneros sobre la Guerra Civil espańola, las Canciones populares de la guerra de independencia de España (1936-1939), que le habían quedado. A su vuelta, los repartió entre la gente.

30. Archivo personal Roberto Pérez Castro, sin título, presumiblemente 1959, notas, s. p. Por otro lado, hay un documento que me despierta algunas dudas respecto al repertorio. Se trata de Roberto Pérez Castro, "Palabras para el estreno del I9 de julio de 1946", mecanoescrito, s. p. Allí se dice que el espectáculo de esa noche (al que no se menciona) "inaugura la temporada del presente año". Eso es llamativo teniendo en cuenta que Guerrillas de la liberación se habría 


\section{Concepción sobre el teatro}

Es interesante pensar desde qué perspectivas el grupo Teatro Libre de Buenos Aires miraba el teatro. En principio, se advierte que en el documento que planteaba las "Bases provisorias" se expresaba: "Bajo el nombre de "Teatro Libre de Bs. As.', se halla reunido un grupo de voluntades dispuestas a revalorizar el arte teatral." ${ }^{31}$ Si hay que revalorar el arte teatral, es decir, volver a otorgarle valor, se entiende que, implícitamente, se está hablando de cierto contexto teatral en el que el teatro está siendo degradado. Este tipo de intención había sido muy popular en los inicios del teatro independiente, cuando lo que más se destacaba era el teatro profesional producido por empresarios, cuyas características eran consideradas de bajo nivel por muchos artistas e intelectuales. Sin embargo, para agosto de 1944, ya se habían creado una gran cantidad de teatros independientes. ¿Eran éstos los destinatarios del mensaje subliminal de las "Bases provisorias"? Entiendo que no y que era otra la cuestión. A partir del golpe de Estado de 1943 - "única experiencia de una intervención militar contra un gobierno conservador", ${ }^{32}$ como lo fue el de la Década Infame ${ }^{33}$-, los

estrenado en febrero. A su vez, la única referencia a la obra que se da en ese texto es que se trataba de un homenaje a Romain Rolland: "Y como no hay mejor ejemplo que la acción, hemos creído oportuno iniciar esta temporada, rindiendo un cariñoso homenaje al gran maestro de la juventud y de la humanidad, Romain Rolland, y recogiendo el sentimiento que siempre animó su obra y su vida, dedicamos esta función de estreno, al cumplirse el $\mathrm{IO}^{\circ}$ aniversario del levantamiento nazi-falangista, al heroico pueblo de España Republicana, que aún lucha contra la tiranía que le oprime”. Desconozco si se trata de un error de fechas o de algún proyecto que se planeó, pero no se terminó de concretar. Asimismo, en otro texto encontrado en el archivo (una biografía de Roberto Pérez Castro) se mencionaba que la obra Pedro y Lucía, de Romain Rolland, se había llevado a escena como parte del periódico escénico Estudio. Nélida Agilda — consultada al respecto - también recuerda que esta obra se representó, aunque no aporta mayores datos. Como no he logrado cotejar esta información en los programas de mano reproducidos, dejo asentada la duda, y me pregunto si éste es el espectáculo que se había preparado o estrenado en homenaje a Rolland.

3I. Archivo personal, Teatro Libre de Buenos Aires, "Bases provisorias para el grupo Teatro Libre de Buenos Aires", mecanoescrito, s. f., s. p.

32. Carlos Fos, El viejo municipal. El sistema de producción público y su relación con el teatro independiente (Buenos Aires: Editorial Nueva Generación, 20I4), 58.

33. La Década Infame — como se conoce al periodo argentino transcurrido entre 1930 y 1943- se inició con un golpe de Estado — apoyado por grupos políticos conservadores, élites oligarcas y medios de comunicación- que derrocó al gobierno de Hipólito Yrigoyen el 6 de septiembre de 1930. Tuvo cuatro gobiernos, del mismo color político: al de José Félix Uri- 
tres teatros independientes más reconocidos del momento habían sido expulsados de las salas que, previamente, les había cedido la municipalidad. El caso del Teatro del Pueblo fue el más extremo (porque implicaba la derogación de la ordenanza 8.612, de 1937, que indicaba que se le confería el edificio de la Av. Corrientes $153 \mathrm{O}^{34}$ por veinticinco años y porque, aparte, se realizó un desalojo violento), pero también sufrieron las consecuencias La Máscara y el Teatro Juan B. Justo. Si tenemos en cuenta que Roberto Pérez Castro y otros integrantes del Teatro Libre se iniciaron en el último grupo mencionado; que, a pesar de las excusas brindadas por el gobierno, se percibía que la decisión de las expulsiones tenía tintes ideológicos, y que para algunos teóricos la sustracción de las sedes para estos grupos representó el fin de la primera etapa del teatro independiente, ${ }^{35}$ podemos pensar que el receptor de la crítica — culpable de una supuesta desvaloración- podía ser un Estado que se "entrometía" en el campo teatral independiente.

Asimismo, al reflexionar sobre el tipo de teatro que pretendía hacer el Teatro Libre de Buenos Aires, se advierte que sí se proponía incidir en la sociedad en la que se encontraba inmerso. En una nota dirigida a los cooperadores del grupo (sin fecha, pero por el contenido se constata que no es anterior a 1946), Roberto Pérez Castro sostuvo:

Teniendo en cuenta que todas las fuerzas sanas de la República contribuirán a establecer una democracia efectiva para nuestro pueblo, el Teatro, como lo hizo desde un primer momento, colaborará entusiastamente en la empresa, y en ese sentido tiene ya comprometidas varias funciones a realizarse en su local y fuera de él.

buru-Enrique Santamarina le siguieron, mediante elecciones nacionales (pero fraudulentas), los mandatos de Agustín Pedro Justo-Julio Argentino Pascual Roca (1932-I938), Roberto Marcelino Ortiz-Ramón Castillo (1938-I942), y Ramón Castillo (1942-I943).

34. En ese edificio luego se construyó el Teatro Municipal de Buenos Aires, actual Teatro General San Martín.

35. Ordaz dijo entonces que el movimiento de teatros independientes constituía una "parábola cerrada" y una "hermosa obra cumplida"; Ordaz, El teatro en el Río de la Plata, 193-194. En I957 se retractó. Es decir, reconoció la decadencia de la que había dado cuenta a finales de 1945 a partir del desalojo de sus salas del Teatro del Pueblo, el Teatro Juan B. Justo y La Máscara, pero sostuvo que eso dio lugar no a la finalización del movimiento de teatros independientes, sino al cierre de una etapa y a la posterior apertura de otra; Luis Ordaz, El teatro en el Río de la Plata (Buenos Aires: Leviatán, 1957). A mi modo de ver, la etapa fundacional del movimiento duró hasta 1944, cuando se da la institucionalización del movimiento mediante el surgimiento de la Fati (Federación Argentina de Teatros Independientes). 
Es también propósito de sus integrantes, siempre que se pueda, ofrecer espectáculos breves y de realización modesta, a la manera de "Guerrillas", que permitan la fácil y eficaz divulgación de ideas tendientes a fortalecer el ánimo de la ciudadanía. ${ }^{36}$

Éste no es el único documento en el que se puede rastrear la intención de injerir en la sociedad civil y la caracterización del teatro como un bien de utilidad pública. En otra declaración de principios reproducida en el cuadernillo de extensión cultural, se destacó que el Teatro Libre tendría dos metas:

Fin social

Favorecer la formación y el desarrollo de una conciencia artístico-social de profunda raigambre humana entre los colaboradores y amigos, que estimule y organice la capacidad de lucha, de amor y creación necesarias para conseguir el ideal trazado. Fin artístico

Difundir la buena literatura y el buen teatro sin distinción de épocas o nacionalidades, y entregarlo puro y vigorizado al pueblo, de donde emana y a quien pertenece. ${ }^{37}$

De acuerdo con estas palabras, una vez más queda expresado que el Teatro Libre pretendía despertar conciencias y transformar lo que estuviera a su alcance por medio del arte teatral, a la vez que éste debía ser puro, valioso y popular. En tales declaraciones se encuentran rastros de todo un camino recorrido por el teatro independiente, incluso desde antes de que se iniciara en Buenos Aires, en tanto que se perciben las tres líneas - teatro libre/independiente, teatro de arte, teatro popular- en las que clasifiqué las figuras y los grupos del teatro europeo que he considerado como antecedentes del teatro independiente porteño. ${ }^{38}$

La última de estas tres corrientes, que ubicaba al pueblo en el centro de los destinatarios del teatro, tenía como referente a Romain Rolland, figura venerada por muchos teatros independientes, desde Leónidas Barletta y su Teatro del Pueblo, pasando por La Máscara — cuyo lema fue durante un tiempo "Con los ideales de Romain Rolland”- y llegando al Teatro Libre de Buenos Aires. En este teatro no sólo se colgó un retrato suyo que decía "Su Patria: la humanidad / Su causa: la libertad / Y amaba a Francia...” (tengamos en cuenta que

36. Archivo personal, Roberto Pérez Castro, "Estimado cooperador", volante, s. f., s. p.

37. Teatro Libre de Buenos Aires. Esencia y función, I, s. p.

38. Véase Fukelman, "Influencias del teatro europeo", I59-178. 
el autor francés había fallecido recientemente, el 30 de diciembre de 1944), sino también, como ya he dicho, lo citaban con diversas frases que el grupo imprimía y daba de recuerdo al público. Una de ellas era: "Nosotros no ponemos la gloria del espíritu humano al servicio del pueblo; hacemos un llamado al pueblo para que, con nosotros, se ponga al servicio de esa gloria." De igual manera, Roberto Pérez Castro también definió al teatro popular, aquel que pretendía hacer con los teatros independientes que dirigió a lo largo de su vida:

Es popular todo lo que se comunica vitalmente con las fuerzas del pueblo, todo aquel arte que atiende a su problemática múltiple y compleja. En estos momentos en que el mundo está sacudido por tremendas conmociones: guerras, dictaduras, ambiciones, intereses, explotaciones, destrucciones, colonialismo, depresión, corrupción, etc. no se puede considerar populares a las obras que plantean problemas estéticos, formales, individuales o patológicos, eludiendo, soslayando lo humano, lo que [es] general, para atender lo particular. ${ }^{39}$

Es decir, que la manera en que concebía y entendía al teatro estaba comprometida con su época, y era capaz de contribuir a la difusión de problemáticas trascendentales y a la transformación positiva del pueblo, para hacerlo reflexionar y actuar en consecuencia.

\section{Dirección y disciplina}

La disciplina, la manera correcta de comportarse que debían tener los participantes del Teatro Libre de Buenos Aires, era algo sumamente importante para el grupo. De los ocho artículos que tienen las "Bases provisorias", cinco se vinculan con esta temática. Además, en uno de los tres restantes, también se hace alusión al deber ser de cada integrante, en tanto que se sostiene que "sólo la buena voluntad y la cooperación y contracción al estudio y al trabajo" ${ }^{40}$ permitirían el cumplimiento de los fines propuestos.

Los artículos dedicados exclusivamente a dejar en claro qué características debían tener los colaboradores y cuáles serían sus obligaciones indican:

39. Archivo personal, Roberto Pérez Castro, "Sin título", mecanoescrito, s. f., presumiblemente 1959, s. p.

40. Archivo personal, Roberto Pérez Castro, Teatro Libre de Buenos Aires, "Bases provisorias para el grupo Teatro Libre de Buenos Aires", mecanoescrito, s. f, s. p. 
$4^{\circ}$ Únicamente se considerará colaborador a aquel que con su trabajo constante contribuya al sostenimiento del grupo, permitiendo que cumpla el fin propuesto. $5^{\circ}$ Los miembros serán aceptados por la Dirección y figurarán como aspirantes durante el término de un ańo, sujetos a todos los deberes que exige esta reglamentación sin gozar de los derechos correspondientes. Al cumplirse ese periodo serán o no confirmados como colaboradores.

$6^{\circ}$ Se podrá suspender o expulsar a un colaborador o aspirante:

a) Por mayoría de las tres cuartas partes de los colaboradores del grupo, aunque no intervenga la dirección [...].

b) La dirección podrá suspender o expulsar a los miembros que a su juicio incurran en falta, correspondiendo a una mayoría de las tres cuartas partes, las mismas prerrogativas que le asisten al director en el inciso (a) de este artículo, si así lo desearan, de suspender la pena por tres meses hasta nueva y definitiva sanción, que se aplicará en la forma más conveniente para el grupo [...]. $7^{\circ} \mathrm{La}$ reincidencia de un colaborador suspendido por segunda vez, producirá a la tercera su automática expulsión.

$8^{\circ}$ No podrá volver al grupo ningún colaborador o aspirante expulsado.

Son deberes de los colaboradores:

a) Evitar la brusquedad, de palabra o de hecho, en el trato, con los demás;

b) Cuidar de la salud física y moral. El desalińo, la holganza, los malos hábitos, la falta de interés por instruirse, se consideran falta de respeto hacia sí y hacia los demás;

c) Asistir puntualmente a las reuniones, no retirarse antes de su terminación e informarse de la fecha, lugar y hora de la próxima, en caso de haber faltado a alguna de ellas;

d) No actuar por cuenta propia en festivales, radio, etc., ni invocar el nombre del grupo sin autorización del director;

e) No hacer observaciones de orden técnico a los compañeros. Toda sugerencia debe ser dirigida al director;

f) Efectuar la limpieza y arreglo de los camarines, lugares y útiles de trabajo;

g) Estar quince minutos antes de la hora seńalada para dar comienzo al espectáculo, completamente listos, aquellos que intervengan en el mismo;

h) Si se realizan espectáculos fuera del local, los colaboradores que en él intervengan estarán en el lugar de partida diez minutos antes de la hora seńalada para la misma. Quienes se dirijan directamente al lugar del espectáculo, lo avisarán con anterioridad y estarán treinta minutos antes de la hora señalada para el comienzo de la función. 
La falta a una función sin aviso previo y justificado produce automáticamente la exoneración..$^{4 r}$

En esta extensa cita, se presentan varias cuestiones que vale la pena destacar. Una de ellas es el respeto por el otro, la solidaridad, el compañerismo que se pretendía que reinara en el grupo y que, quizá, se intentaba imponer, desde la teoría, mediante el rigor. Como contraparte de esto se puede pensar en cierta falta de empatía para las situaciones particulares, ya que los artistas no vivían del teatro y tenían o debían tener otro trabajo con el cual colmar sus necesidades básicas, hecho que podía generar, quizá, por ejemplo, alguna llegada tarde. No obstante, se entiende que estas bases no se escribieron antes de iniciar las acciones del teatro sino un tiempo después, por lo que se advierte que muchas de estas medidas disciplinares pudieron haber sido consecuencias de experiencias negativas previas. La otra cuestión a destacar es la situación de primacía que debía tener el director respecto del grupo. Él - en este caso, Roberto Pérez Castro- era el encargado de autorizar a los actores y actrices para que hablaran en medios de comunicación o actuaran en festivales. Asimismo, era quien debía centralizar cualquier comentario que surgiera entre los integrantes del grupo a la hora de señalar cuestiones técnicas. Supongo también que la redacción de estas directivas, tan específicas, se vinculaba con situaciones pasadas que habían generado discordia y que se pretendían evitar en el futuro. Este lugar preponderante para el director como el que dominaba el centro de la escena y de las decisiones se sostenía (o se había sostenido) en otros grupos de teatro independientes, e incluso se consideraba uno de los cambios instaurados por el movimiento de teatros independientes en torno a la dirección teatral:

La figura del director en el teatro de Buenos Aires, que se modifica a partir del nacimiento sistematizado del Teatro independiente con Leónidas Barletta, desde la inauguración del Teatro del Pueblo el 30 de noviembre de 1930, convirtió el trabajo de dirección en una función esencial para el desarrollo de la puesta, subordinando el trabajo de los actores a su mirada. ${ }^{42}$

4I. Archivo personal, Roberto Pérez Castro, Teatro Libre de Buenos Aires, "Bases provisorias para el grupo Teatro Libre de Buenos Aires", mecanoescrito, s. f., s. p.

42. Azucena Joffe y María de los Ángeles Sanz, "Directoras argentinas contemporáneas", Revista Afuera, V (2010): s. p., consultado en enero de 20I8, en http://www.revistaafuera.com/ articulo.php?id=I97\&nro=8\#textor. 
Si bien ésta fue la situación del ya mencionado caso prototípico de Barletta en el Teatro del Pueblo — acusado muchas veces de autoritario-, o la de Ricardo Passano en La Máscara, es importante destacar que no había una única manera de ejercer roles de dirección. ${ }^{43}$

Muchos años más tarde, en 1960, Roberto Pérez Castro se refirió —en una mesa redonda organizada en la Universidad de Buenos Aires, y compartida con Mirta Arlt, Pablo Antón, Marcela Sola y Andrés Lizárraga — a la libertad que debía ejercer el director de una obra teatral. Según sus palabras, éste sólo podía ocupar su papel correctamente si:

Interviene en la elección de la pieza

Determina el reparto

Se expide sobre el escenógrafo que habrá de colaborar

Se le asegura un mínimo de posibilidades económicas

Influye en el tono de la propaganda

Supervisa, sin intervenir directamente, las relaciones públicas

Y, muy especialmente, dispone de amplia libertad para concretar todos estos pasos sin presiones internas o externas al Teatro, que generalmente nada tienen que ver con él, y sí con el interés de una minoría que gobierna en contra de la comunidad. ${ }^{44}$

\section{Cultura y educación}

La preparación del Teatro Libre de Buenos Aires antes de hacer su primera obra (sistematizar los libros con los que contaban en su biblioteca) no sólo tenía que ver con buscar material para llevar a escena, sino también con un objetivo superador: la formación actoral. Así lo mencionó Roberto Pérez Castro en el documento que leyó la noche del estreno de Estudio. Publicación Escenificada:

Esta parte teórica de la primera etapa tenía una aspiración inmediata: ordenar un plan de formación del actor y trazar las bases de un plan directivo. Y siempre en

43. Véase María Fukelman, "Mujeres en la historia del movimiento de teatros independientes de Buenos Aires: aportes para la historia de La Cortina y el Teatro Espondeo", Revista Interdisciplinaria de Estudios de Género de El Colegio de México 4, núm. 290 (2018): I-28.

44. Archivo personal, Roberto Pérez Castro, "Mesa redonda en los cursos preparatorios organizados en la Universidad de Buenos Aires", mecanoescrito, 2 de febrero de 1960, s. p. 
el terreno de los proyectos, que es tan fácil llevarse de ellos, pensamos en realizar una publicación oral, si fuera posible totalmente escenificada, que nos sirviera de experiencia práctica.

Luego, ya con mayores conocimientos, y más seguros de nuestras inquietudes, entraríamos en una segunda etapa, con la ordenación de un Teatro Libre que llevara en esencia nuestra orientación artística y un sentido democrático de lo social, y con la creación de un teatro para niños, además de otros proyectos generosos que, por lo lejanos, y para no cansar vuestra atención, dejaremos por hoy a un lado.45

De acuerdo con estos conceptos hay que leer las notas que se entregaron en el intervalo de esta primera función (y que luego se repetirían en otras funciones). Allí se pedía colaboración al público con la difusión del espectáculo y se refería al propio Teatro Libre como una "escuela de teatro" ${ }^{46}$ En todas estas palabras, es evidente que las intenciones del grupo iban más allá de montar obras de teatro. No obstante, no existe registro de que estos otros objetivos, como el armado de un teatro para nińos o el funcionamiento real de una escuela de teatro, se hubieran podido llevar a cabo.

Asimismo, siguiendo la intención de incidir de manera favorable en la sociedad y de visibilizar su mirada sobre la realidad, el Teatro Libre editó con su propio sello (Ediciones del Teatro Libre de Buenos Aires) un cancionero sobre la Guerra Civil española, denominado Canciones populares de la guerra de independencia de España (1936-1939). Es sabido que el grupo dirigido por Roberto Pérez Castro se manifestó incontables veces en contra de las guerras. Un ejemplo se puede ver en un documento fechado el I9 de julio de 1946, donde el propio director dice:

Sin dudas saben ustedes el terrible desequilibrio que en todos los órdenes ocasionan las guerras. El saldo inconmensurable de destrucción moral y material que dejó esta última. Así lo afirman personas de juicio sereno, que cuentan, para asegurarse, con la experiencia recogida en sus propios pueblos y en otros que fueron actores en la tremenda lucha. ${ }^{47}$

45. Archivo personal, Roberto Pérez Castro, "Palabras leídas en la noche del rer Estreno, 22 de junio de 1945", mecanoescrito, s. p.

46. Archivo personal, Roberto Pérez Castro, Teatro Libre de Buenos Aires, sin título, 22 de junio de i945, volante, s. p.

47. Archivo personal, Roberto Pérez Castro, "Palabras para el estreno del i9 de julio de 1946", mecanoescrito, s. p. 
Además, el grupo publicó el ya mencionado cuadernillo de extensión cultural número I, titulado Teatro Libre de Buenos Aires. Esencia y función - material sumamente valioso para la escritura del presente trabajo-, con parte de la historia del grupo, las obras que representaron y algunas notas que se referían a ellas. Estos dos títulos editados por el grupo independiente contaron con el mismo isologotipo, en el que se puede leer "la palabra en el viento".

En el cuadernillo, asimismo, el grupo propone determinadas acciones de extensión cultural. Si bien no es posible saber a ciencia cierta si éstas formaron parte de una declaración de propósitos o si efectivamente (todas o algunas) se llevaron a cabo, allí se lee sobre: ciclo de conferencias ilustradas; lecturas comentadas; publicaciones; y funciones gratuitas en colegios, instituciones, fábricas, plazas, entre otros.

\section{Vinculos con el teatro profesional y los recursos económicos}

A partir del lema de Francisco Giner de los Ríos que acogió el Teatro Libre de Buenos Aires, ya aludido antes, es posible interpretar que el "desinterés en los móviles" hacía referencia a los motivos económicos. En este sentido, el grupo dirigido por Pérez Castro se manejó como el común de los teatros independientes: careció de fines de lucro. No obstante, de manera irremediable tuvo que tener ciertos vínculos con el dinero para poder continuar sus acciones.

Algunos de sus ingresos provenían de las entradas de los espectáculos que, de todas maneras, eran muy accesibles. En las primeras dos temporadas de Estudio. Publicación Escenificada, el precio de la entrada era de \$0.50, bastante bajo si tenemos en cuenta que, para 1946, un albañil estaba cobrando alrededor de $\$ 9$ por día. Y también resulta muy económico si se considera que, en 1943, los teatros "comerciales" cobraban $\$ 1.70$ por entrada. ${ }^{8}$ A su vez, el grupo se sostenía gracias al aporte de los colaboradores, amigos o personas del público en general que eran invitadas a suscribirse mediante notas que se repartían en los intervalos de las funciones. Las instrucciones para convertirse en "cooperador" indicaban que se debía hacer por medio de una solicitud de suscripción que se retiraba en boletería. Contra entrega de la colaboración, se otorgaba

48. Véase Ana Jaramillo, comp., El peronismo y la justicia social. Reproducción de la obra gráfica publicada por la presidencia de la nación, en el año del libertador general San Martín I95o (Remedios de Escalada: Universidad Nacional de Lanús, 2012). 
un cartoncito a modo de recibo con el logo del Teatro Libre de Buenos Aires. Y una vez que se formaba parte del grupo de cooperadores, se recibían notas de parte del grupo en las que se avisaba de los próximos estrenos, entre otras cuestiones. También — como fue el caso del II de agosto de 1945- se les invitaba a integrarse de una manera más comprometida:

USTED puede colaborar más estrechamente con nosotros si gana la propia confianza y sabe canalizar su individualismo. Diga con los jóvenes del teatro libre DE BUENOS AIREs: "No soy más que uno, pero soy uno. No puedo hacerlo todo, pero puedo hacer algo. Lo que puedo hacer, debo hacerlo. Y lo que debo hacer, lo haré considerando al hombre un fin en sí mismo y con el imperativo categórico de hacer el bien como un cumplimiento del deber." Y si siente los ideales de este Teatro como propios, y la necesidad de ayudarle a mejorar sus espectáculos, ofrezca sus servicios de intérprete, escritor, técnico, en la seguridad de que sabremos valorar y respetar su colaboración, siempre que ella se ajuste a nuestro lema: "Nobleza en los fines, honradez en los medios, desinterés en los móviles." ${ }^{4}$

Por su parte, el grupo les hacía llegar a aquellos colaboradores el estado de las cuentas, a la vez que les aclaraba que aún no habían sido elegidas las autoridades revisoras. En 1945 , el Teatro Libre contaba con un saldo en la caja de $\$ 80.40$ y con una deuda de \$513 al grupo fundador, que lo había otorgado en calidad de préstamo. Los ingresos del grupo provenían de dinero donado por los fundadores (\$137.45; además de los $\$ 568$ que habían dado a préstamo y de los cuales ya les habían devuelto $\$ 55)$, de la venta de entradas (\$426.60), de las cuotas mensuales de los cooperadores (\$383.50) y de "entradas varias" (\$49.85). Asimismo, este dinero se había utilizado para los siguientes ítems: efectos de luz (\$449.70), construcción del escenario (\$90.95), maquillaje (\$92.50), alquiler de trajes (\$127), derechos pagados en Argentores (\$155), ayuda con los gastos de Nueva Argentina (\$173), impresos (\$122.50) y "gastos varios" (\$219.35).

En 1958, en un escrito que estaba destinado a ser publicado en el periódico de la FATI, Roberto Pérez Castro defendió la figura de la cooperativa como vínculo de trabajo en los teatros independientes, pero también consideró "una urgente necesidad" la profesionalización de esta práctica. Además de resolver las cuestiones económicas, la profesionalización — si se lograba efectivizar- iba a agosto de 1945, volante, s. p. 
permitir "suprimir ciertas barreras que nos separan del campo profesional para llegar a constituir la gran familia de profesionales del teatro capaces y responsables que habrán de consolidar una auténtica dramática nacional". ${ }^{\circ}$ En este sentido, consideró la posibilidad de que artistas profesionales se sumaran al teatro independiente (al mismo tiempo de que advirtió que algunas cuestiones del teatro independiente habían modificado al teatro profesional) y sostuvo que, si eso sucedía, no debía influir solamente su popularidad, sino también otras características: "Los intérpretes que se sumen al Teatro Independiente deben poseer capacidad, disciplina, y conducta, puesto que el Teatro Independiente tiene una ética." ${ }^{\text {"r }} \mathrm{Si}$ bien estas palabras fueron expresadas más de diez años después de terminar la labor con el Teatro Libre, permiten suponer que, si aún en ese momento los ámbitos "profesionales" e "independientes" se encontraban distantes, en la época en que Pérez Castro, efectivamente, había estado al frente de su primer teatro independiente, sus vínculos con el teatro profesional no habían sido demasiado profundos..$^{22}$

\section{Relaciones con el Estado y con los partidos politicos}

En el documento de "Bases provisorias" del Teatro Libre de Buenos Aires hay un apartado que sostiene:

Considerando la misión de este grupo puramente artística en beneficio de la sensibilidad del pueblo, queda excluida toda experimentación que no contemple los fines propuestos, como así también todo plan orientado a imponer una determinada tendencia política, religiosa o filosófica. ${ }^{53}$

50. Archivo personal, Roberto Pérez Castro, "Para el periódico de la fati", mecanoescrito, 28 de junio de 1958 , s. p.

5I. Archivo personal, Roberto Pérez Castro, "Para el periódico de la FATI", mecanoescrito, 28 de junio de 1958 , s. p.

52. Aunque estos comentarios quedan fuera de mi estudio sobre el Teatro Libre de Buenos Aires, es interesante dar cuenta del análisis que, un año después, Pérez Castro hizo sobre cierta mala orientación que estaban tomando tanto el teatro profesional como el independiente, espacios que, según él, "en estos últimos tiempos entremezclaron intereses"; Archivo personal, Roberto Pérez Castro, "Desorientación de nuestro teatro", mecanoescrito, 2 de octubre de 1959, s. p.

53. Archivo personal, Roberto Pérez Castro, Teatro Libre de Buenos Aires, "Bases provisorias para el grupo Teatro Libre de Buenos Aires", mecanoescrito, s. f., s. p. 
Una vez más, esta declaración tiene vestigios de experiencias anteriores del teatro independiente, especialmente del Teatro del Pueblo. En los estatutos del grupo pionero se había sostenido algo similar: "Siendo su misión, puramente artística como excitante espiritual. El Teatro del Pueblo es ajeno a toda tendencia política, religiosa o filosófica." ${ }^{44}$ Pero así como el Teatro del Pueblo no fue por completo ajeno a toda tendencia política (por ejemplo, en su revista Metrópolis, se hizo campaña explícita por la fórmula presidencial de Lisandro de la Torre y Nicolás Repetto, de la Alianza Demócrata Socialista), se entiende que el Teatro Libre tampoco. En principio, como he mencionado, sus obras se llevaron a cabo en algunas circunscripciones del Partido Socialista. Esto es algo que el Teatro Juan B. Justo (en el que, recordemos, Pérez Castro y varios integrantes del grupo se habían iniciado) había hecho en numerosas oportunidades. Además, la situación de "hacer campaña" con su espectáculo Guerrillas..., representándolo hasta tres veces por día en febrero de 1946, nos advierte sobre lo comprometidos que estaban los artistas del Teatro Libre de Buenos Aires con la coyuntura política que los rodeaba (y también esperanzados, porque en enero de 1946 afirmaban en las cartas a sus cooperadores que en ese año iba a tener lugar el "triunfo de la democracia en la República Argentina").55 De manera que, si se hacían numerosas representaciones, en plena campaña electoral, para que no ganara un candidato en particular, hay que advertir que eso no estaba tan lejos de pretender imponer determinada tendencia política, como se estipulaba en las "Bases provisorias". Si se interpretan las declaraciones asentadas en el documento, desde otro punto de vista, podrían leerse como una intención de separarse de lo partidario más que de la política en sí; no obstante, el hecho de haber realizado funciones en alguna sede del Partido Socialista desmentiría igualmente que esas bases se hubieran cumplido con rigurosidad.

Asimismo, es importante destacar que la tendencia política del Teatro Libre de Buenos Aires tenía varias justificaciones. Para empezar, estaba la inscripción propia dentro del movimiento de teatros independientes, es decir, la continuación de cierta tradición opositora (de distinto grado) que habían tenido los grupos predecesores hacia los gobiernos de la Década Infame. El Teatro Juan B. Justo había sido un fervoroso actor político del Partido Socialista. No sólo

54. Raúl Larra, Leónidas Barletta. El hombre de la campana (Buenos Aires: Ediciones Conducta, I978), 8I.

55. Archivo personal, Roberto Pérez Castro, "Estimado señor", volante, 27 de enero de 1946, s. p. 
se había iniciado en el seno de esta institución (como Agrupación Artística Popular) y luego había tomado el nombre de uno de sus máximos referentes, sino que también había actuado en sus sedes, había suspendido los ensayos en campaña electoral para que sus integrantes pudieran estar en los centros socialistas y había salido a hacer funciones junto a la comisión nacional electoral (entre otras cuestiones). A su vez, cuando tuvo lugar el golpe de Estado de I943, la oposición entre teatros independientes y gobierno se recrudeció, en tanto que este último expulsó de las salas municipales ${ }^{56}$ que les habían sido cedidas, al Teatro del Pueblo, el Teatro Juan B. Justo y a La Máscara. ${ }^{57}$ El hecho de que Juan Domingo Perón — quien, para las elecciones presidenciales de 1946, ya había protagonizado el mítico I7 de octubre de 1945- hubiese integrado este gobierno militar heterogéneo era el primer punto para que muchos teatros independientes le tuvieran desconfianza. Pero no era el único.

Como ya hemos mencionado, Pérez Castro y su conjunto se ocuparon mucho de repudiar la guerra. En uno de sus escritos, el director del Teatro Libre de Buenos Aires dijo:

Cuando las tropas del nazifascismo se extendieron por Europa, la vida de algunos pueblos quedó detenida en un punto muerto de confusión y desesperanza. Se acalló la expresión orientadora de muchos espíritus esforzados, que por su raza, opiniones o religión no compartían la violencia delirante del invasor..$^{58}$

A su vez, también como he enunciado a lo largo de este trabajo, el grupo se solidarizó especialmente con el pueblo español. El cuadernillo que editaron con las canciones que se habían hecho conocidas durante la Guerra Civil o "Guerra de independencia de Espańa” (tal como la presentaron allí) tenía la siguiente dedicatoria: "Homenaje del 'Teatro Libre de Buenos Aires' al heroico pueblo

56. Recordemos que por aquellos años era el presidente de la nación quien designaba al entonces intendente de la ciudad de Buenos Aires, por lo que no es posible separar en distintos signos políticos al gobierno municipal del gobierno nacional.

57. Aunque es cierto que con otros grupos pudo entablar mejores vínculos; véase María Fukelman, "Vínculos posibles entre el movimiento de teatros independientes y el primer peronismo", VI Congreso de Estudios sobre el Peronismo (I943-2018) (Buenos Aires: Red de Estudios sobre el Peronismo, 2019), disponible en http://redesperonismo.org/articulo/vinculos-posibles-entre-el-movimiento-de-teatros-independientes-y-el-primer-peronismo/.

58. Archivo personal, Roberto Pérez Castro, "Noble misión del teatro", recorte periodístico, junio de I948, s. p. 
republicano español, que defiende con tanta dignidad y valentía su derecho a un mundo libre y progresista." ${ }_{9}$ Este conflicto internacional había calado hondo en muchos de los intelectuales de la época y la postura ante él había reorganizado el campo cultural. Al respecto, Flavia Fiorucci sostiene:

En poco tiempo la causa republicana derivó en la conformación de una sociabilidad e identidad antifascista, ya que se fueron haciendo cada vez más numerosas las asociaciones y los mítines cuyo común denominador era aunar fuerzas contra la propagación del fascismo. ${ }^{60}$

Esta situación, asimismo, se profundizó más todavía con el inicio de la segunda guerra mundial. De manera que el golpe militar de 1943 y la irrupción de Perón en la escena política fueron leídos como "la encarnación del fascismo criollo". ${ }^{61}$ La escritora María Rosa Oliver — que había sido fundadora y directora de otro teatro independiente, La Cortina— resumió esta idea algunos ańos más tarde: "Perón había estado de agregado militar en Italia, el grupo de los coroneles, el Gou [Grupo de Oficiales Unidos, del cual Perón era miembro], era germanófilo, conocíamos la mentalidad castrense, entonces dijimos, bueno, ahora lo vamos a tener aquí." ${ }^{62}$ A su vez, no podemos olvidar la cooperación que existió entre Franco y Perón, tanto en la campaña presidencial como en los inicios de su gobierno. ${ }^{63} \mathrm{El}$ año en el que se pretendía estrenar ¿Y España?, además, coincidió con el viaje de Eva Perón a Europa, en el que tuvo lugar, el 8 de junio, su encuentro con el dictador español. De esta manera, se entiende el contexto en el cual el Teatro Libre de Buenos Aires se manifestó en contra de esta emblemática figura argentina y de su gobierno. ${ }^{64}$

59. Archivo personal, Teatro Libre de Buenos Aires, Canciones populares de la guerra de independencia de España (1936-I939) (Buenos Aires: Ediciones del Teatro Libre de Buenos Aires, s. f.), s. p.

60. Flavia Fiorucci, Intelectuales y peronismo 1945-1955 (Buenos Aires: Biblos, 20II), 2I.

6I. Fiorucci, Intelectuales y peronismo, 23.

62. Citado en Fiorucci, Intelectuales y peronismo, 23.

63. Raanan Rein, "El pacto Perón-Franco: justificación ideológica y nacionalismo en Argentina”, Estudios Interdisciplinarios de América Latina y el Caribe I, núm. I (I990): s. p., consultado el 20 de mayo de 2020, en http://eial.tau.ac.il/index.php/eial/article/view/1313/1339.

64. No obstante, desde la actualidad, sería extraño no preguntarnos por la postura del Teatro Libre ante todas las medidas beneficiosas para la clase trabajadora (a la que entendemos que el grupo también defendía, de acuerdo a sus valores expresados) y la ampliación de derechos que propició Perón. En este sentido, es indudable que el gobierno peronista ha tenido cierta 
Años más tarde, inversamente de lo que se había manifestado en el documento de "Bases provisorias" - y bastante más cercano al verdadero accionar de su primer teatro independiente-, Pérez Castro sostuvo:

El hombre de teatro y más aún el de Teatro Independiente debe estar ubicado políticamente, militando o no en el partido que haya escogido. Pero su ubicación o militancia política, que habrá de servirle para consolidar su ideal de hombre de teatro puesto al servicio del pueblo, nunca debe perturbar la vida interna del teatro donde actúe; tampoco insistir para que se haga una propaganda descarnada desde el escenario de su credo político. ${ }^{65}$

Respecto de las relaciones entre el Teatro Libre y el Estado, no hay demasiados registros de que éstas hayan tenido lugar. Al contrario, advirtiendo que el Estado estaba representado por un gobierno al que el grupo tanto defenestraba, se puede prever un vínculo de rechazo:

Sabemos, ya, que el Estado se perfila como dueńo absoluto de toda la vida nacional, y, como es lógico, tratará de encauzar y dirigir a los Teatros Independientes, con el propósito de absorberlos o sustituirlos si no contemplan sus intereses particulares. Pero que esto no suceda o tarde en suceder (nosotros confiamos en la acción tesonera del esfuerzo propio y no queremos acostumbrarnos a que se nos dispense el éxito o la felicidad por decreto), apelaremos a la comprensión del público que nos sigue, para que en la medida de sus fuerzas nos ayude a mantener esta libertad y esta independencia que con tanto celo defendemos, asegurándoles que todo les será devuelto, ya que desinteresadamente servimos a este ideal honrado puesto al servicio del pueblo. ${ }^{66}$

La distancia con el Estado no se achicó con el paso del tiempo. En este sentido, en 1959, Pérez Castro afirmó que los teatros independientes sostuvieron su labor durante treinta ańos "contra la inoperancia de todos los gobiernos que

versatilidad en su sistema de alianzas y enemigos. Sobre este aspecto, Fiorucci sostuvo que los intelectuales antiperonistas ponían ímpetu en "construir un enemigo más coherente ideológicamente de lo que realmente era"; Fiorucci, Intelectuales y peronismo, I74.

65. Archivo personal, Roberto Pérez Castro, "Para el periódico de la FaTi", 28 de junio de 1958, s. p.

66. Archivo personal, Roberto Pérez Castro, "Palabras para el estreno del i9 de julio de I946”, mecanoescrito, I9 de julio de I946, s. p. 
castigan su afán de lucha por un acervo cultural mientras defienden dignamente y a costa de grandes sacrificios principios imprescriptibles e inalienables de democracia y libertad". Y en ese mismo documento, el para ese entonces, ex director del Teatro Libre de Buenos Aires expresó: "Considerando el arte del teatro un bien de utilidad pública, la comunidad tiene la obligación de actuar para que esa oscura realidad se modifique" ${ }^{67}$ De acuerdo con esto, enumeró una serie de medidas que el Estado tenía que tomar para fortalecer al movimiento de teatros independientes (algo que, a su modo de ver, no se había hecho hasta entonces): reducir al máximo posible los alquileres de las salas, suprimiendo a los empresarios intermediarios; solicitar a los consorcios eléctricos el establecimiento de una tarifa de luz reducida; promover la colaboración de comerciantes e industriales mediante ventas al costo de materiales; suprimir impuestos y "en un futuro, cuando la economía del país lo autorice, subvencionar a los más capaces"; ${ }^{68}$ y convertir salones, sótanos y demás dependencias ociosas en pequeños teatros independientes. Todas estas propuestas dan cuenta de que aunque las relaciones entre el movimiento de teatros independientes y el Estado no se habían desarrollado —a los ojos de Pérez Castrode la mejor forma, sí debían comenzar a ejercerse, por lo que al parecer él no era partidario de una independencia absoluta o pura (lugar en el que, desde la teoría, se pretendía encasillar al teatro independiente), sino de una zona de diálogo y cooperación mutua.

\section{Inserción dentro del movimiento de teatros independientes}

En el inicio de este trabajo, advertí que, aunque Roberto Pérez Castro prefería el término "teatro libre" por sobre el de "teatro independiente", eso no implicaba que no reconociera a su grupo como parte del movimiento de teatros independientes. Al contrario, en la gran mayoría de los documentos firmados por él o por el propio Teatro Libre de Buenos Aires se especificaba que el conjunto era un teatro independiente. Esta decisión de reconocerse como parte de una tradición se ve reflejada en varias cuestiones. Si bien no contamos con en el estatuto original del grupo —y sí con las "Bases provisorias", en las que no

67. Archivo personal, Roberto Pérez Castro, "Desorientación de nuestro teatro", mecanoescrito, 2 de octubre de 1959, s. p.

68. Archivo personal, Roberto Pérez Castro, "Desorientación de nuestro teatro", s. p. 
se mencionó la palabra "independiente" - , tenemos el estatuto que el Teatro Juan B. Justo redactó en 1943 por iniciativa de su director Enrique Agilda. ${ }^{69}$ Allí se puede ver cómo Pérez Castro tachó, en el primer artículo, el nombre "Juan B. Justo" al lado de la palabra "Teatro" y lo reemplazó, a mano, por "Libre de Buenos Aires". Aunque desconozco si, efectivamente, el grupo se organizó de acuerdo al estatuto tomado del Teatro Juan B. Justo, la interpretación que hago es que el director del Teatro Libre se basó (o tuvo la intención de hacerlo) en una o varias afirmaciones de las que estaban redactadas ahí para conformar su teatro. Es decir que, de alguna manera, el teatro independiente donde él había comenzado su carrera actoral se constituyó como un posible modelo para su nueva actividad. Además, como ya se vio, hubo varios puntos de las "Bases provisorias" que se pueden emparentar con los estatutos fundacionales del Teatro del Pueblo, el mítico teatro independiente de Leónidas Barletta.

A su vez, apenas el grupo inició sus funciones, declaró su pertenencia al movimiento implícitamente en las palabras mencionadas durante el intervalo de la representación del i2 de octubre de i945:

Sabemos que no bastan las palabras, y por eso ofrecemos el ejemplo de la acción, realizando el ponderable esfuerzo de repetir 27 veces el primer espectáculo. Cumplimos, así, con un principio básico del movimiento de los Teatros Libres o Independientes: realizar temporadas estables a precios reducidos. ${ }^{7 \circ}$

Pérez Castro realizó la misma operación a los pocos meses:

El Teatro Independiente, Señoras y Seńores, ha cometido y comete muchos errores, la mayoría de ellos por los escasos recursos de que dispone y la poca responsabilidad de algunos de sus directores. Justo es reconocerlo. No siempre logra verdadera jerarquía artística en sus espectáculos, y aclaro que en este juicio nos incluimos: pero asimismo es justicia reconocer que sus postulados básicos son nobles y contemplan la elevación espiritual del pueblo y la defensa de sus derechos naturales, con un sentido de amor fraterno que el propio pueblo desconoce. ${ }^{71}$

69. Archivo personal, Teatro Juan B. Justo, "Reglamento interno del Teatro 'Juan B. Justo'”, 1943, s. p.

70. Archivo personal, Teatro Libre de Buenos Aires, sin título, I2 de octubre de 1945, s. p.

7I. Archivo personal, Roberto Pérez Castro, "Palabras para el estreno del i9 de julio de 1946", s. p. 
De manera que se evidencia la pretensión de formar parte de este movimiento artístico y de hacerlo con convicción y tesón. Y si bien no entraremos de lleno en esta clasificación, es justo recordar que Pérez Castro teorizó varias veces sobre el concepto de teatro independiente y la historia del movimiento. ${ }^{72}$ Además, es importante destacar que el reconocimiento del Teatro Libre como parte del teatro independiente también corrió por parte de la crítica. No sólo Ordaz lo mencionó en su mítico El teatro en el Río de La Plata, sino que Marial saludó su creación al poco tiempo de consumarse: "El Teatro Libre de Buenos Aires es una nueva agrupación escénica que llega al tablado independiente en momento oportuno: cuando por diversos factores éste se encuentra realmente disminuido." 73

\section{Palabras finales}

A lo largo de este trabajo he hecho un recorrido por la historia del Teatro Libre de Buenos Aires, surgido en agosto de 1944 y dirigido por Roberto Pérez Castro, y lo he abordado a partir de seis ejes de análisis. Lo pude hacer gracias al archivo personal del propio Pérez Castro, conservado y cedido por su esposa y su hija. En este sentido, logré escribir el primer artículo dedicado a este grupo.

Durante su breve existencia, el Teatro Libre de Buenos Aires llevó a escena al menos tres espectáculos, realizados con base en una modalidad novedosa para la época. Además, estas obras se constituyeron como hechos de denuncia, en tanto que dialogaban tanto con las realidades internacionales que preocupaban al grupo, como con los actores políticos nacionales.

Asimismo, señalé los puntos de contacto que encontré entre el Teatro Libre y otros grupos predecesores, inmersos en el movimiento de teatros independientes. En línea con esto, expuse la forma en que el grupo se inscribió dentro de esta tradición, diferenciándose también con la preferencia por el término "libre".

72. Véase Roberto Pérez Castro, "El Teatro Independiente en la Argentina", Boletín de Estudios de Teatro, s. f., 34-37; y Teatro Libre de Buenos Aires. Esencia y función, I.

73. Teatro Libre de Buenos Aires. Esencia y función, I, s. p. 
Por último, desarrollé las posibles relaciones entre el grupo de Pérez Castro, el teatro profesional y el Estado, a la vez que expuse las formas de subsistencia económica del Teatro Libre.

Recuperar la historia de distintos grupos de teatro independiente contribuye a dar mayores muestras de las particularidades de este movimiento tan heterogéneo, a la vez que visibiliza experiencias poco consideradas por la historiografía oficial. Por todo lo expuesto, reivindico el recorrido del Teatro Libre de Buenos Aires y espero que se puedan conocer a profundidad muchas otras experiencias históricas del rico y diverso teatro independiente porteño. \$ 